\title{
An observational study of once-daily modified-release methylphenidate in ADHD: the effect of previous treatment on ADHD symptoms, other externalising symptoms and quality-of-life outcomes
}

\author{
Manfred Döpfner • Dieter Breuer • Daniel Walter • \\ Aribert Rothenberger
}

Published online: 8 September 2011

(c) The Author(s) 2011. This article is published with open access at Springerlink.com

\begin{abstract}
Methylphenidate (MPH) is the most commonly prescribed stimulant for children with ADHD. Data on the effects of different MPH formulations in real-life settings are scarce, and the role of previous therapy on treatment outcome when switching medications has not been well studied. OBSEER was an observational study designed to evaluate the effectiveness and safety of Equasym $\mathrm{XL}^{\circledR}$ in routine care. This study assessed whether the improvements reported with Equasym $\mathrm{XL}^{\circledR}$ are influenced by the degree of symptom control achieved with the previous medication. Patients enrolled in OBSEER were stratified by prior treatment (none, MPH-immediate release [IR] once daily [o.d.] [MPH-IR o.d.], MPH-IR repeated [MPHIR >o.d.] and MPH-MR [modified release] excluding Equasym $\mathrm{XL}^{\circledR}$ ), and changes in ADHD and other externalising symptoms (CGI-S, FBB-ADHD and DAYAS) and quality of life (QoL, KINDL) were evaluated during treatment with Equasym XL ${ }^{\circledR}$. A total of 782 patients were analysed. Significant group-by-time interactions were found for all symptom variables analysed, indicating that effects varied by previous medication. For CGI-S and FBB-ADHD total scores, the greatest reductions in ADHD
\end{abstract}

M. Döpfner · D. Breuer · D. Walter

Department of Child and Adolescent Psychiatry,

University of Cologne, Cologne, Germany

M. Döpfner $(\bowtie)$

Department of Psychiatry and Psychotherapy of Childhood

and Adolescence, University of Cologne,

Robert-Koch-Str. 10, 50931 Cologne, Germany

e-mail: manfred.doepfner@uk-koeln.de

A. Rothenberger

Department of Child and Adolescent Psychiatry,

University of Göttingen, Göttingen, Germany symptoms were observed in the treatment-naïve subgroup, followed (in order) by MPH-IR o.d., MPH-IR >o.d. and MPH-MR. A similar profile was seen for DAYAS ratings for all periods of the day except the evening, when there were no significant differences between subgroups. Similarly, the treatment-naïve and MPH-IR o.d. subgroups showed the greatest improvements in KINDL ratings. Although effects were greatest for treatment-naïve patients, improvements were also observed in the prior treatment subgroups for symptoms and QoL. This suggests that a change to Equasym $\mathrm{XL}^{\circledR}$ may be beneficial in patients with suboptimal effects on prior medication.

Keywords ADHD - Observational study .

Quality of life · Treatment - Methylphenidate · Predictor

\section{Introduction}

The use of stimulants for the treatment of attention deficit hyperactivity disorder (ADHD) in children and adolescents is known to provide significant short-term improvements both in the core symptoms of the disease (inattention, hyperactivity and impulsivity) and in the behavioural problems associated with it (e.g. aggressive behaviour, depressive mood, anxiety, tics, impaired social functioning and academic productivity) [22].

Methylphenidate (MPH) is the most commonly prescribed stimulant for children with ADHD. It is characterised by a short half-life of $2-3 \mathrm{~h}$ and reaches its maximum effect 1.5-2 $\mathrm{h}$ after dosing [21]; therefore, immediate-release (IR) MPH formulations require repeated administration during the day in order to maintain effectiveness, and 2-3 daily doses are normally needed for most children [15]. As multiple dosing can cause adherence 
issues and problems in terms of privacy, stigmatisation by classmates and potential abuse [13], several long-acting MPH formulations have been developed in the past few years that combine IR and modified-release (MR) components, allowing rapid onset of therapeutic effect and sufficient duration to eliminate the need for additional doses. All available long-acting preparations provide a mixture of MPH-IR and -MR, but differ in the type of modified delivery system used and in the proportion of IR-to-MR components [3], which results in distinct pharmacokinetic profiles over time; this is reflected by patterns of efficacy and action on behaviour throughout the day that are specific for each long-acting MPH formulation [3, 22]. Equasym $\mathrm{XL}^{\circledR 1}$ (Shire Pharmaceuticals Ireland Limited, Ireland) combines 30\% MPH-IR and 70\% MPH-MR, producing a fast initial increase in MPH plasma concentration followed by a second increase approximately $3 \mathrm{~h}$ later and maintaining therapeutic concentration for about $8 \mathrm{~h}[20,24]$; it has been shown to be as effective as MPHIR given twice daily [12].

Although different MPH preparations have been compared directly in randomised clinical trials-such as the COMACS study [22] or the above-mentioned study comparing Equasym $\mathrm{XL}^{\circledR}$ and MPH-IR [12]—empirical data on the effects of different MPH formulations in a natural, real-life setting are scarce. Results from a European openlabel study investigating the effectiveness and tolerability of a long-acting MPH formulation (osmotic release oral system [OROS] MPH [Concerta ${ }^{\circledR}$, Janssen-Cilag Ltd, UK]) in children and adolescents treated previously with MPHIR revealed that symptom control was maintained or improved after switching to the long-acting formulation; the improvement was more evident to parents than teachers, possibly reflecting increased symptom control in the second part of the day after school [17]. Another open-label study analysed the effect of abrupt conversion from a stable dose of oral MPH-MR to an MPH transdermal system (Daytrana ${ }^{\circledR}$, Noven Therapeutics LLC, Miami, USA) showing that the transdermal system may further improve ADHD symptoms and quality of life (QoL) when titrated carefully [2,6]. However, none of these studies considers different previous therapies and specifically compares their influence on treatment outcome when patients are switched to a different medication.

In another observational study, Döpfner et al. examined the effectiveness and tolerability of an MPH-MR

\footnotetext{
${ }^{1}$ Equasym XL is the UK trade name, and is registered and marketed by Shire in the following countries under the following trademarks: Denmark, Equasym Depot; Finland, Equasym Retard; France, Quasym LP; Germany, Equasym Retard; Ireland, Equasym XL; Netherlands, Equasym XL; Norway, Equasym Depot; Sweden, Equasym Depot; South Korea, Metadate CD; Mexico, Metadate CD. Information correct at August 2011.
}

preparation with a 50\% IR component (Medikinet ${ }^{\circledR}$ Retard/ XL, Medice, Germany) in 447 patients aged 6-17 years with ADHD, and with an indication for treatment with this preparation [9]. ADHD symptom severity declined significantly. Oppositional behaviour and side effects as rated by parents were also reduced. The authors found the strongest effects in treatment-naïve children, and somewhat weaker effects in children who had received previous treatment with an alternative MPH on the different outcome measures tested.

The OBSEER (OBservation of Safety and Effectiveness of Equasym $\mathrm{XL}^{\circledR}$ in Routine care) study $[8,19]$ was a noninterventional, post-marketing surveillance study conducted in Germany to evaluate the effectiveness and safety of Equasym XL ${ }^{\circledR}$ under routine care conditions. It included children diagnosed with ADHD or hyperkinetic disorder (HKD) either previously untreated or treated with different formulations of MPH, who started treatment with, or were switched to, Equasym $\mathrm{XL}^{\circledR}$.

To test the hypothesis that the extent of improvement reported with Equasym $\mathrm{XL}^{\circledR}$ is influenced by the degree of symptom control achieved with a previous medication, patients enrolled in the OBSEER study were stratified according to prior treatment, and changes in ADHD symptoms, other externalising symptoms and QoL were evaluated during treatment with Equasym $\mathrm{XL}^{\circledR}$.

\section{Methods}

Participants and study design

OBSEER was a post-marketing observational study of Equasym $\mathrm{XL}^{\circledR}$, designed primarily to assess effectiveness and safety in clinical practice and conducted in 169 centres in Germany in accordance with local regulations and under the therapeutic responsibility of the attending physicians; ethics or institutional review board approval was not required for this study. Written informed consent was obtained from parents. The study included children aged 6-17 years with a confirmed diagnosis of ADHD according to the Diagnostic and Statistical Manual of the American Psychiatric Association (DSM-IV-TR) [1] or HKD according to the International Classification of Diseases (ICD-10) [25], for whom therapy with Equasym $\mathrm{XL}^{\circledR}$ was already planned by the treating physician. Details regarding study design and participants are described elsewhere in this supplement [8]. For this analysis, patients enrolled in the OBSEER study were stratified by pharmacological treatment received prior to study initiation. Four subgroups were considered: treatment-naïve, MPH-IR once daily (o.d.; MPH-IR o.d.), MPH-IR more than o.d. (MPH-IR $>$ o.d.) and MPH-MR other than Equasym XL ${ }^{\circledR}$. Children 
who had previously been administered drugs other than MPH or for whom prior treatment was not specified were not included in the analysis.

\section{Outcome measures}

Measures of ADHD symptoms and QoL in the OBSEER study were obtained using the following tools.

1. German ADHD symptom checklist (Fremdbeurteilungsbogen für Aufmerksamkeitsdefizit-Hyperaktivitätsstörung, FBB-ADHD) $[5,10,11]$. FBB-ADHD is part of the German diagnostic system for mental disorders in children and adolescents (DISYPS-II) [10] and assesses 20 symptom items, which are rated by teachers and parents on a scale ranging from $0=$ not at all, to $3=$ very much, with higher scores indicating more severe symptoms. Nine symptom items are combined into a subscale assessing inattention, and 11 items are combined to assess hyperactivity and impulsivity; the total symptom score covers all 20 symptom items. In addition, four items evaluate functional impairment with respect to school performance, relationship towards adults and children, and the subjective level of suffering (functional impairment subscale), and six items assess competences regarding attentive, reflexive and enduring behaviour (attention-reflexivity subscale).

2. ADHD-Clinical Global Impression-Severity (ADHDCGI-S). A scale assessing ADHD core symptoms (inattention, hyperactivity and impulsivity) and diseaseassociated problems (aggressive behaviour, depressive mood, anxiety, tics and learning difficulties).

3. Day profile of ADHD symptoms (DAYAS) [4]. DAYAS assesses the daily profile of ADHD and other externalising symptoms from early morning until bedtime. A teacher version of the questionnaire (DAYAS-T) considers the first and second part of the morning at school. This complements the parent version (DAYAS-P), which covers the remaining four daily periods: early morning (before school), early afternoon until $4.00 \mathrm{pm}$, late afternoon until $7.00 \mathrm{pm}$ and evening. The rating scale evaluates six items: (1) hyperactivity, (2) inattention, (3) impulsivity, (4) oppositional behaviour, (5) aggressive behaviour and temper tantrums and (6) a global rating of problem behaviour. A subscale, ADHD symptoms, comprises items $1-3$, and items 4 and 5 are combined into a second subscale, oppositional defiant disorder $(O D D)$ symptoms. For each period, parents and teachers rate each item on a four-point scale using the following values: $0=$ not at all; $1=$ just a little; $2=$ pretty much; 3 = very much.
4. Kinder Lebensqualitätsfragebogen (KINDL). A questionnaire for the assessment of health-related QoL [16]. This is a short, validated tool comprising 24 items, with six subscales (physical well-being, emotional well-being, self-esteem, family, friends and school). Three different versions were used according to age group: KID-KINDL (children aged 6-11 years old), the self-reported KIDDO-KINDL (adolescents aged 12-17 years old) and KINDL for parents of patients aged 6-17 years old.

Details about these instruments, as well as their use and results in the OBSEER study, are described elsewhere in this supplement $[4,8,19]$.

Statistical analysis

As described above, the study sample was divided based on previous medication into four subgroups (treatment naïve, MPH-IR o.d., MPH-IR >o.d. and alternative MPH-MR formulation). Post hoc multivariate analyses of variance (MANOVA) were conducted with the four groups as between-subject factor, and with the repeated assessment at Visits 1, 2 and 3 as within-subject factor. Effect sizes [14, 18] were calculated post hoc as indicators of symptom change using Cohen's $d$ [7] for dependent samples, by dividing the difference between the means of Visit 1 and Visit 3 with a variable including the pooled standard deviations (SD) for Visits 1 and 3, and the bivariate correlation $(r)$ between the two visits, as follows:

$d=\frac{\text { Mean }_{\text {Visit1 }}-\mathrm{Mean}_{\mathrm{Visit} 3}}{\sqrt{\left(\mathrm{SD}_{\mathrm{Visit} 1}\right)^{2}+\left(\mathrm{SD}_{\mathrm{Visit} 3}\right)^{2}-2 * r_{\mathrm{Visit1}, \mathrm{Visit} 3} * \mathrm{SD}_{\mathrm{Visit1}} * \mathrm{SD}_{\mathrm{Visit3}}}}$

\section{Results}

Patient characteristics

This analysis included 782 of the 852 patients enrolled in the OBSEER study; children for whom the information regarding previous therapy was unclear were not considered, and those treated previously with medications other than MPH were also excluded due to the reduced group size. Baseline characteristics stratified by previous MPH treatment, ADHD diagnosis and daily MPH dosage are presented in Table 1. Statistically significant differences between previous medication subgroups were found for age (MANOVA: $F(3,764)=3.28 ; P=0.020$ ), with older children in the MPH-IR >o.d. and MPH-MR subgroups. Between the three subgroups treated previously with MPH, daily MPH dosage also varied significantly (MANOVA: $F(2,521)=64.52 ; P<0.001)$, being highest in the MPHMR group, followed by the MPH-IR >o.d. group. 
Table 1 Baseline patient characteristics stratified by previous medication

ICD International Classification of Diseases [25], IR immediate release, $M P H$ methylphenidate, $M R$ modified release, o.d. once daily, $S D$ standard deviation

${ }^{\text {a }}$ Prior to treatment with Equasym XL ${ }^{\circledR}$

\begin{tabular}{|c|c|c|c|c|}
\hline & \multicolumn{4}{|c|}{ Previous treatment $(N=782)$} \\
\hline & $\begin{array}{l}\text { None } \\
(n=208)\end{array}$ & $\begin{array}{l}\text { MPH-IR o.d. } \\
(n=101)\end{array}$ & $\begin{array}{l}\text { MPH-IR >o.d. } \\
(n=270)\end{array}$ & $\begin{array}{l}\text { MPH-MR } \\
(n=203)\end{array}$ \\
\hline \multicolumn{5}{|l|}{ Baseline demographics } \\
\hline Males, \% & 80.3 & 79.2 & 80.4 & 82.2 \\
\hline Age, years (mean $[\mathrm{SD}])$ & $9.76(2.74)$ & $9.78(2.25)$ & $9.94(2.40)$ & $10.46(2.29)$ \\
\hline \multicolumn{5}{|l|}{ ADHD diagnosis (ICD code), $\%$} \\
\hline F90.0: disturbance of activity/attention & 48.1 & 46.5 & 56.3 & 57.1 \\
\hline F90.1: hyperkinetic conduct disorder & 33.2 & 31.7 & 34.8 & 35.0 \\
\hline F90.8: other hyperkinetic disorders & 11.1 & 10.9 & 6.7 & 4.9 \\
\hline $\begin{array}{l}\text { Daily MPH dosage at Visit } 1^{\mathrm{a}} \text {, } \\
\text { mg (mean [SD]) }\end{array}$ & - & $14.13(7.48)$ & $23.99(10.88)$ & $29.15(11.28)$ \\
\hline
\end{tabular}

\section{ADHD and ODD symptoms}

Physician (ADHD-CGI-S), parent and teacher ratings (FBB-ADHD) of ADHD symptoms at each study visit stratified by prior treatment, MANOVA results (group effect and group-by-time interaction effect) and effect sizes (Cohen's $d$ ) are shown in Table 2. For the FBB-ADHD scale, the subscales inattention and hyperactivity/impulsivity gave similar results and are, therefore, presented combined as total symptom score, along with the functional impairment and attentive, reflexive and enduring behaviour (attention-reflexivity subscale) scores.

The main effect of time was highly significant on all outcome measures (data not shown), indicating significant symptom improvement across the three assessment points. Significant between-group effects were also observed on most variables, and group-by-time interactions were significant for all outcomes analysed, indicating different effects for different previous medications (Table 2).

Reductions in ADHD symptoms during treatment with Equasym $\mathrm{XL}^{\circledR}$ (from Visit 1 to Visit 3 ) as assessed by clinicians on the ADHD-CGI-S scale are shown as effect sizes (Cohen's $d$ ) in Fig. 1a. The largest reduction was observed in the treatment-naïve subgroup $(d=1.73)$, followed in order of decreasing reduction by MPH-IR o.d., MPH-IR $>$ o.d. and MPH-MR $(d=0.76)$. Although the effect sizes for FBB-ADHD parameters were somewhat smaller (Fig. 1b), the same profile was observed for parent and teacher ratings (FBB-ADHD total score), with the largest changes being found in the subgroup without prior medication. For teacher ratings, effect sizes in the subgroups with previous medication were smaller than for parent ratings.

Parent and teacher ratings of ADHD and ODD symptoms (DAYAS-P and DAYAS-T total scores) at each study visit during different periods of the day, with the corresponding MANOVA results and effect sizes, are shown in
Table 3; separate analyses for the DAYAS ADHD and $O D D$ symptoms subscales gave similar results (data not shown). Significant group-by-time interactions were observed for all parts of the day, except the evening (DAYAS-P), when no significant differences between subgroups were found. Figure 2 illustrates the reductions in ADHD and ODD symptoms during treatment with Equasym $\mathrm{XL}^{\circledR}$ (effect sizes) on the DAYAS-P and DAYAS-T scales. For parent ratings, the largest reductions in ADHD and ODD symptoms between Visit 1 and Visit 3 were observed in the early and late afternoon for all subgroups, except MPH-MR, while changes in the morning and evening were generally smaller. The most marked differences between groups were also found during the early and late afternoon, with symptom reduction most pronounced in the subgroup with no previous medication. For teacher ratings, the subgroup without previous medication showed substantial improvements in ADHD and ODD symptoms both in the first and second half of the school morning. Changes were moderate in the MPH-IR subgroups and smaller in the MPH-MR subgroup, in particular during the first half of the morning.

\section{Quality of life}

Parent (KINDL) and patient (KID-KINDL, 6-11 years old) ratings of QoL stratified by previous medication, with main effects of group and group-by-time interactions (MANOVA) and effect sizes (Cohen's $d$ ), are reported in Table 4. Ratings by patients aged 12-17 years on the KIDDOKINDL scale were not considered because subgroups in this age range were too small for this type of analysis. The main effects of time were highly significant for all outcome parameters (data not shown). For parent-rated QoL (KINDL), significant group-by-time interactions were found for the total score and the subscales self-esteem, friends and school, but not for physical well-being, emotional well-being and family. Effect sizes for the total score 
Table 2 ADHD symptoms rated by physicians, parents and teachers stratified by previous medication with main group effect, group-by-time interaction effect (MANOVA) and effect sizes (Cohen's $d$ )

\begin{tabular}{|c|c|c|c|c|c|c|c|c|c|c|}
\hline \multirow[t]{2}{*}{ Outcome measure } & \multirow[t]{2}{*}{$\begin{array}{l}\text { Previous } \\
\text { treatment }\end{array}$} & \multirow[t]{2}{*}{$n$} & \multirow{2}{*}{$\begin{array}{l}\text { Visit } 1 \\
\text { Mean (SD) }\end{array}$} & \multirow{2}{*}{$\begin{array}{l}\text { Visit } 2 \\
\text { Mean (SD) }\end{array}$} & \multirow{2}{*}{$\begin{array}{l}\text { Visit } 3 \\
\text { Mean (SD) }\end{array}$} & \multicolumn{2}{|c|}{$\begin{array}{l}\text { MANOVA } \\
\text { group }\end{array}$} & \multicolumn{2}{|c|}{$\begin{array}{l}\text { MANOVA } \\
\text { group-by- } \\
\text { time } \\
\text { interaction }\end{array}$} & \multirow{2}{*}{$\begin{array}{l}\text { Effect size } \\
\text { Cohen's } d \\
\text { (Visit 1-Visit 3) }\end{array}$} \\
\hline & & & & & & $F$ & $P$ & $F$ & $P$ & \\
\hline \multicolumn{11}{|l|}{ Clinical rating (CGI-S) } \\
\hline \multirow[t]{4}{*}{ Global impression } & None & 154 & $2.27(0.57)$ & $1.40(0.66)$ & $1.00(0.63)$ & 3.35 & 0.019 & 9.81 & 0.000 & 1.73 \\
\hline & MPH-IR o.d. & 77 & $2.10(0.66)$ & $1.38(0.67)$ & $0.96(0.75)$ & & & & & 1.29 \\
\hline & MPH-IR >o.d. & 213 & $1.88(0.70)$ & $1.26(0.73)$ & $1.02(0.61)$ & & & & & 1.11 \\
\hline & MPH-MR & 164 & $1.88(0.64)$ & $1.36(0.69)$ & $1.24(0.65)$ & & & & & 0.76 \\
\hline \multicolumn{11}{|l|}{ Parent rating ( $F B B-A D H D)$} \\
\hline \multirow[t]{4}{*}{ Total score } & None & 185 & $1.81(0.62)$ & $1.16(0.61)$ & $0.95(0.55)$ & 3.66 & 0.012 & 9.97 & 0.000 & 1.41 \\
\hline & MPH-IR o.d. & 86 & $1.73(0.61)$ & $1.19(0.60)$ & $1.07(0.61)$ & & & & & 1.15 \\
\hline & MPH-IR >o.d. & 234 & $1.49(0.63)$ & $1.06(0.55)$ & $0.98(0.52)$ & & & & & 0.85 \\
\hline & MPH-MR & 165 & $1.54(0.57)$ & $1.25(0.58)$ & $1.11(0.58)$ & & & & & 0.79 \\
\hline \multirow[t]{4}{*}{ Functional impairment } & None & 185 & $2.06(0.65)$ & $1.34(0.69)$ & $1.04(0.64)$ & 8.28 & 0.000 & 11.19 & 0.000 & 1.36 \\
\hline & MPH-IR o.d. & 86 & $1.87(0.73)$ & $1.39(0.69)$ & $1.24(0.71)$ & & & & & 0.81 \\
\hline & MPH-IR >o.d. & 233 & $1.65(0.75)$ & $1.19(0.72)$ & $1.05(0.72)$ & & & & & 0.70 \\
\hline & MPH-MR & 165 & $1.78(0.72)$ & $1.59(0.73)$ & $1.36(0.73)$ & & & & & 0.53 \\
\hline \multirow{4}{*}{$\begin{array}{l}\text { Attentive, reflexive } \\
\text { and enduring behaviour }\end{array}$} & None & 185 & $0.72(0.57)$ & $1.16(0.64)$ & $1.32(0.59)$ & 2.93 & 0.033 & 6.32 & 0.000 & 0.93 \\
\hline & MPH-IR o.d. & 87 & $0.80(0.60)$ & $1.11(0.60)$ & $1.17(0.71)$ & & & & & 0.54 \\
\hline & MPH-IR >o.d. & 233 & $1.01(0.64)$ & $1.21(0.66)$ & $1.27(0.67)$ & & & & & 0.37 \\
\hline & MPH-MR & 165 & $0.91(0.63)$ & $1.04(0.60)$ & $1.10(0.63)$ & & & & & 0.27 \\
\hline \multicolumn{11}{|c|}{ Teacher rating ( $F B B-A D H D)$} \\
\hline \multirow[t]{4}{*}{ Total score } & None & 140 & $1.56(0.70)$ & $0.98(0.61)$ & $0.74(0.49)$ & 0.66 & 0.579 & 14.16 & 0.000 & 1.38 \\
\hline & MPH-IR o.d. & 66 & $1.25(0.74)$ & $0.97(0.62)$ & $0.91(0.63)$ & & & & & 0.51 \\
\hline & MPH-IR >o.d. & 162 & $1.16(0.71)$ & $1.00(0.63)$ & $0.88(0.62)$ & & & & & 0.43 \\
\hline & MPH-MR & 124 & $1.20(0.62)$ & $1.07(0.63)$ & $0.99(0.58)$ & & & & & 0.41 \\
\hline \multirow[t]{4}{*}{ Functional impairment } & None & 141 & $1.82(0.82)$ & $1.21(0.77)$ & $0.86(0.65)$ & 2.82 & 0.039 & 11.22 & 0.000 & 1.17 \\
\hline & MPH-IR o.d. & 65 & $1.45(0.89)$ & $1.12(0.77)$ & $1.03(0.79)$ & & & & & 0.49 \\
\hline & MPH-IR >o.d. & 160 & $1.25(0.88)$ & $1.06(0.82)$ & $0.93(0.82)$ & & & & & 0.40 \\
\hline & MPH-MR & 125 & $1.42(0.85)$ & $1.28(0.84)$ & $1.12(0.74)$ & & & & & 0.42 \\
\hline \multirow{4}{*}{$\begin{array}{l}\text { Attentive, reflexive and } \\
\text { enduring behaviour }\end{array}$} & None & 139 & $0.80(0.54)$ & $1.15(0.61)$ & $1.32(0.64)$ & 0.75 & 0.523 & 6.46 & 0.000 & 0.78 \\
\hline & MPH-IR o.d. & 66 & $0.99(0.68)$ & $1.12(0.71)$ & $1.21(0.70)$ & & & & & 0.33 \\
\hline & MPH-IR >o.d. & 158 & $1.09(0.65)$ & $1.22(0.64)$ & $1.25(0.62)$ & & & & & 0.29 \\
\hline & MPH-MR & 121 & $1.08(0.62)$ & $1.14(0.64)$ & $1.18(0.62)$ & & & & & 0.20 \\
\hline
\end{tabular}

$C G I-S$ Clinical Global Impression-Severity (ADHD core symptoms and associated problems), $F B B$ - $A D H D$ Fremdbeurteilungsbogen für Aufmerksamkeitsdefizit-Hyperaktivitätsstörung, $I R$ immediate release, MANOVA multivariate analysis of variance, $M P H$ methylphenidate, $M R$ modified release, o.d. once daily

were in the moderate-to-large $(\geq 0.5)$ range, with largest changes in the treatment-naïve and MPH-IR o.d. subgroups. Effect sizes for MPH-IR >o.d. and MPH-MR were smaller and very similar. In patient-rated QoL (KIDKINDL), significant group-by-time interactions were found for the total score and the subscales self-esteem, family, friends and school, but not for physical well-being and emotional well-being. Effect sizes for the total score varied from small to large, with most pronounced changes in the treatment-naïve subgroup. Effect sizes for the other subgroups were smaller and very similar.

Figure 3a illustrates the improvements in parent-rated QoL (KINDL) by subgroup from Visit 1 to Visit 3 (effect sizes) on the three subscales that showed significant group-by-time interactions (self-esteem, friends and school). 
Fig. 1 Reduction in a clinicianrated (CGI-S) and $\mathbf{b}$ parent- and teacher-rated ADHD symptoms (FBB-ADHD total score) from Visit 1 to Visit 3 in different previous medication subgroups, expressed as effect size (Cohen's $d$ ). CGI-S Clinical Global Impressions-Severity, $F B B-A D H D$

Fremdbeurteilungsbogen für AufmerksamkeitsdefizitHyperaktivitätsstörung, $I R$ immediate release, $M R$ modified release, $M P H$ methylphenidate, o.d. once daily

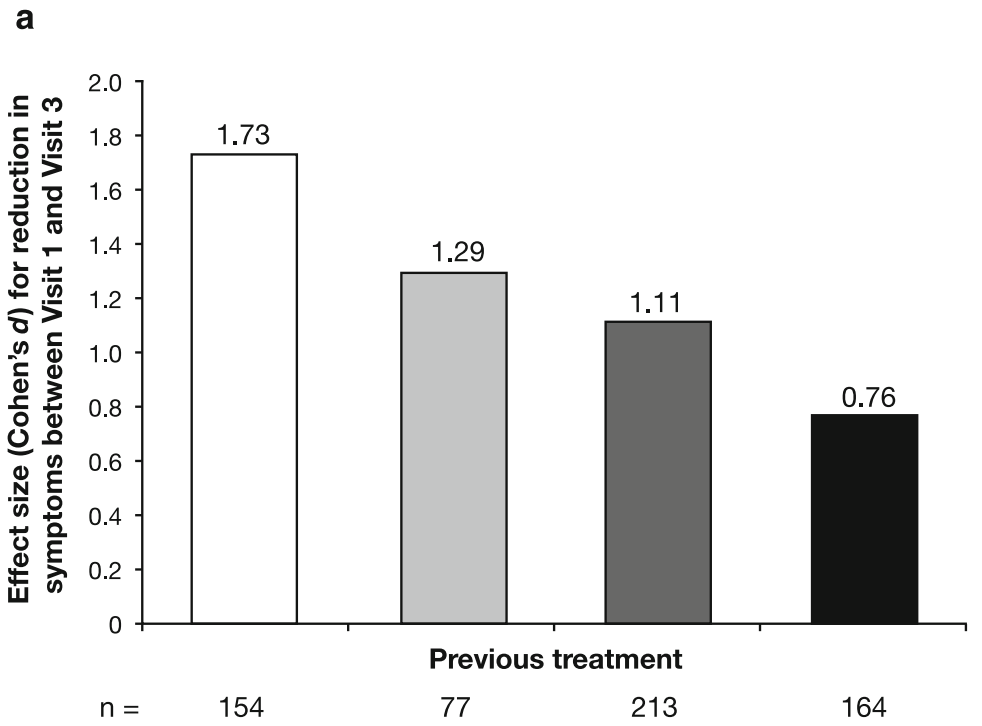

a None

b

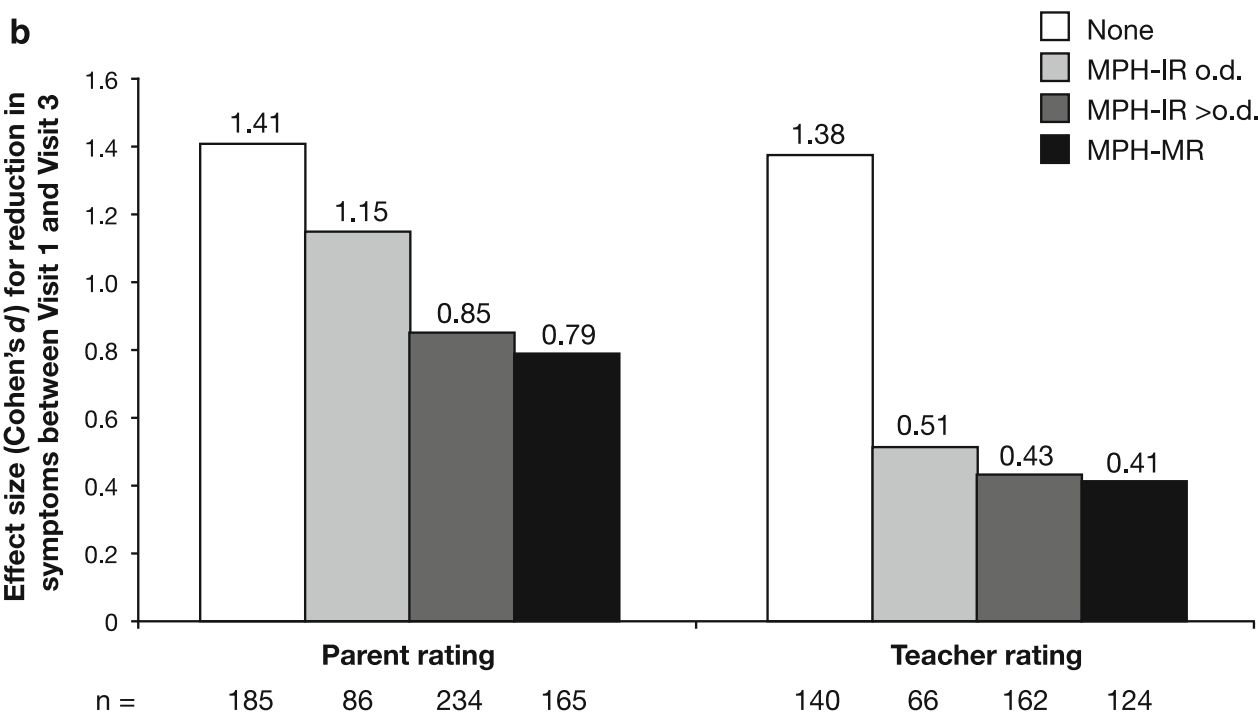

The largest effect sizes were observed for school, except for MPH-MR, which had the largest effect on friends. In all subscales, the treatment-naïve and MPH-IR o.d. subgroups showed the most dramatic improvements during treatment with Equasym $\mathrm{XL}^{\circledR}$; in the other subgroups, effect sizes were smaller and comparable across all three subscales.

Similarly, Fig. 3b shows the improvements in patientrated QoL (KID-KINDL) from Visit 1 to Visit 3 for the four subscales with significant group-by-time interactions (self-esteem, friends, school and family).

Again, in all subgroups, the largest effect sizes were observed for school except for MPH-MR, which had the largest effect on family. The treatment-naïve and MPH-IR o.d. subgroups showed the most dramatic improvements during treatment with Equasym $\mathrm{XL}^{\circledR}$ in all subscales. In the other subgroups, effect sizes were smaller and comparable across subscales.

\section{Discussion}

The hypothesis for this post hoc analysis of the data obtained from the OBSEER study was that the effect size of the improvements observed with Equasym $\mathrm{XL}^{\circledR}$, as assessed by rating of ADHD symptoms, ODD symptoms and QoL, should depend on the degree of symptom control achieved with the previous medication. Following this hypothesis, the strongest effect of Equasym XL ${ }^{\circledR}$ should be observed in patients without previous medication, while substantial but smaller effects should be observed in children treated previously with MPH-IR o.d. Effects in the MPH-IR >o.d. or MPH-MR subgroups should be more moderate and somewhat lower than MPH-IR o.d.

As expected, during Equasym $\mathrm{XL}^{\circledR}$ treatment in the OBSEER study, the largest changes in ADHD symptoms, ODD symptoms and QoL, were observed in the treatment- 
Table 3 ADHD and ODD symptoms rated by teachers and parents for different parts of the day (DAYAS total score) stratified by previous medication with main group effect, group-by-time interaction effect (MANOVA) and effect sizes (Cohen's $d$ )

\begin{tabular}{|c|c|c|c|c|c|c|c|c|c|c|}
\hline \multirow[t]{2}{*}{ Outcome measure } & \multirow[t]{2}{*}{ Previous treatment } & \multirow[t]{2}{*}{$N$} & \multirow{2}{*}{$\begin{array}{l}\text { Visit } 1 \\
\text { Mean (SD) }\end{array}$} & \multirow{2}{*}{$\begin{array}{l}\text { Visit } 2 \\
\text { Mean (SD) }\end{array}$} & \multirow{2}{*}{$\begin{array}{l}\text { Visit } 3 \\
\text { Mean (SD) }\end{array}$} & \multicolumn{2}{|c|}{$\begin{array}{l}\text { MANOVA } \\
\text { group }\end{array}$} & \multicolumn{2}{|c|}{$\begin{array}{l}\text { MANOVA } \\
\text { group-by- } \\
\text { time } \\
\text { interaction }\end{array}$} & \multirow{2}{*}{$\begin{array}{l}\text { Effect size } \\
\text { Cohen's } d \\
\text { (Visit 1-Visit 3) }\end{array}$} \\
\hline & & & & & & $F$ & $P$ & $F$ & $P$ & \\
\hline \multicolumn{11}{|c|}{ Parent rating (DAYAS-P total score) } \\
\hline \multirow[t]{4}{*}{ Morning before school } & None & 182 & $1.29(0.75)$ & $0.95(0.65)$ & $0.88(0.63)$ & 11.15 & 0.000 & 3.45 & 0.002 & 0.60 \\
\hline & MPH-IR o.d. & 86 & $1.20(0.73)$ & $0.97(0.66)$ & $0.95(0.71)$ & & & & & 0.37 \\
\hline & MPH-IR >o.d. & 224 & $1.33(0.79)$ & $0.97(0.71)$ & $0.97(0.69)$ & & & & & 0.53 \\
\hline & MPH-MR & 163 & $1.54(0.73)$ & $1.39(0.77)$ & $1.23(0.79)$ & & & & & 0.49 \\
\hline \multirow[t]{4}{*}{ Afternoon } & None & 177 & $1.72(0.70)$ & $1.07(0.65)$ & $1.07(0.65)$ & 2.99 & 0.014 & 8.77 & 0.000 & 1.24 \\
\hline & MPH-IR o.d. & 86 & $1.54(0.66)$ & $1.15(0.64)$ & $1.15(0.64)$ & & & & & 0.75 \\
\hline & MPH-IR > o.d. & 217 & $1.36(0.67)$ & $1.01(0.62)$ & $1.01(0.62)$ & & & & & 0.67 \\
\hline & MPH-MR & 163 & $1.43(0.60)$ & $1.17(0.61)$ & $1.17(0.61)$ & & & & & 0.63 \\
\hline \multirow[t]{4}{*}{ Late afternoon } & None & 181 & $1.69(0.73)$ & $1.27(0.67)$ & $1.14(0.60)$ & 1.92 & 0.125 & 2.91 & 0.008 & 0.88 \\
\hline & MPH-IR o.d. & 87 & $1.61(0.69)$ & $1.29(0.64)$ & $1.21(0.70)$ & & & & & 0.59 \\
\hline & MPH-IR >o.d. & 226 & $1.54(0.68)$ & $1.23(0.66)$ & $1.17(0.65)$ & & & & & 0.54 \\
\hline & MPH-MR & 164 & $1.61(0.59)$ & $1.43(0.57)$ & $1.31(0.64)$ & & & & & 0.45 \\
\hline \multirow[t]{4}{*}{ Evening } & None & 179 & $1.38(0.80)$ & $1.21(0.72)$ & $1.10(0.66)$ & 6.04 & 0.000 & 0.92 & 0.480 & 0.38 \\
\hline & MPH-IR o.d. & 87 & $1.50(0.75)$ & $1.22(0.74)$ & $1.22(0.77)$ & & & & & 0.37 \\
\hline & MPH-IR >o.d. & 226 & $1.43(0.72)$ & $1.22(0.72)$ & $1.15(0.72)$ & & & & & 0.41 \\
\hline & MPH-MR & 164 & $1.64(0.67)$ & $1.49(0.70)$ & $1.36(0.71)$ & & & & & 0.44 \\
\hline \multicolumn{11}{|c|}{ Teacher rating (DAYAS-T total score) } \\
\hline \multirow[t]{4}{*}{ Morning first half } & None & 140 & $1.31(0.71)$ & $0.81(0.57)$ & $0.59(0.45)$ & 1.22 & 0.301 & 10.84 & 0.000 & 0.99 \\
\hline & MPH-IR o.d. & 64 & $1.06(0.75)$ & $0.86(0.70)$ & $0.74(0.68)$ & & & & & 0.49 \\
\hline & MPH-IR >o.d. & 162 & $0.91(0.74)$ & $0.78(0.63)$ & $0.72(0.63)$ & & & & & 0.28 \\
\hline & MPH-MR & 122 & $0.96(0.68)$ & $0.93(0.70)$ & $0.87(0.65)$ & & & & & 0.14 \\
\hline \multirow[t]{4}{*}{ Morning second half } & None & 138 & $1.64(0.81)$ & $1.06(0.66)$ & $0.83(0.58)$ & 1.06 & 0.366 & 8.43 & 0.000 & 1.09 \\
\hline & MPH-IR o.d. & 61 & $1.27(0.74)$ & $1.01(0.69)$ & $0.94(0.74)$ & & & & & 0.46 \\
\hline & MPH-IR >o.d. & 153 & $1.29(0.81)$ & $1.07(0.70)$ & $0.96(0.69)$ & & & & & 0.45 \\
\hline & MPH-MR & 116 & $1.36(0.78)$ & $1.20(0.79)$ & $1.10(0.74)$ & & & & & 0.39 \\
\hline
\end{tabular}

$D A Y A S-P /-T$ day profile of ADHD symptoms - parent/teacher rating, IR immediate release, MANOVA multivariate analysis of variance, $M P H$ methylphenidate, $M R$ modified release, o.d. once daily, $O D D$ oppositional-defiant disorder, $S D$ standard deviation

naïve subgroup, followed by patients treated previously with MPH-IR o.d., MPH-IR >o.d. and MPH-MR; this was consistently confirmed on all of the rating scales used for ADHD symptoms here, specifically CGI-S (clinical rating), FBB-ADHD and DAYAS (parent and teacher ratings), as well as on the KINDL scales of self-esteem, friends and school (parent and patient ratings) and family (patient ratings only) for QoL.

The effect sizes for ADHD symptoms (FBB-ADHD) in the subgroup without previous medication were approximately 1.4 for both parent and teacher ratings, which is very close to the results obtained in a recent meta-analysis of the efficacy of short-acting MPH [23]. In this meta- analysis, the standardised pre- to post-assessment score change (mean weighted Cohen's $d$ ) was 1.53 (95\% confidence intervals [CI]: 1.23-1.82) for parent ratings and 1.83 (95\% CI: 1.43-2.12) for teacher ratings. Thus, similar changes during MPH treatment can be found in treatmentnaïve groups in both randomised controlled trials and observational trials. Conversely, in another observational study analysing the effectiveness of a different long-acting MPH formulation (Medikinet ${ }^{\circledR}$ Retard/XL) [9], the effect size for parent-rated ADHD and ODD symptoms (DAYAS total score) was 1.1 in the subgroup without previous medication, which is somewhat lower than the effects observed in the present study on the FBB-ADHD scale. 
Fig. 2 Reduction in parent (morning before school, afternoon, late afternoon and evening) and teacher ratings (first half of school morning and second half of school morning) of ADHD and ODD symptoms for different parts of the day (DAYAS total score) by previous medication subgroup, expressed as effect size (Cohen's $d$ ) from Visit 1 to Visit 3. DAYAS day profile of ADHD symptoms, $I R$ immediate release, $M R$ modified release, MPH methylphenidate, o.d. once daily, $O D D$ oppositionaldefiant disorder

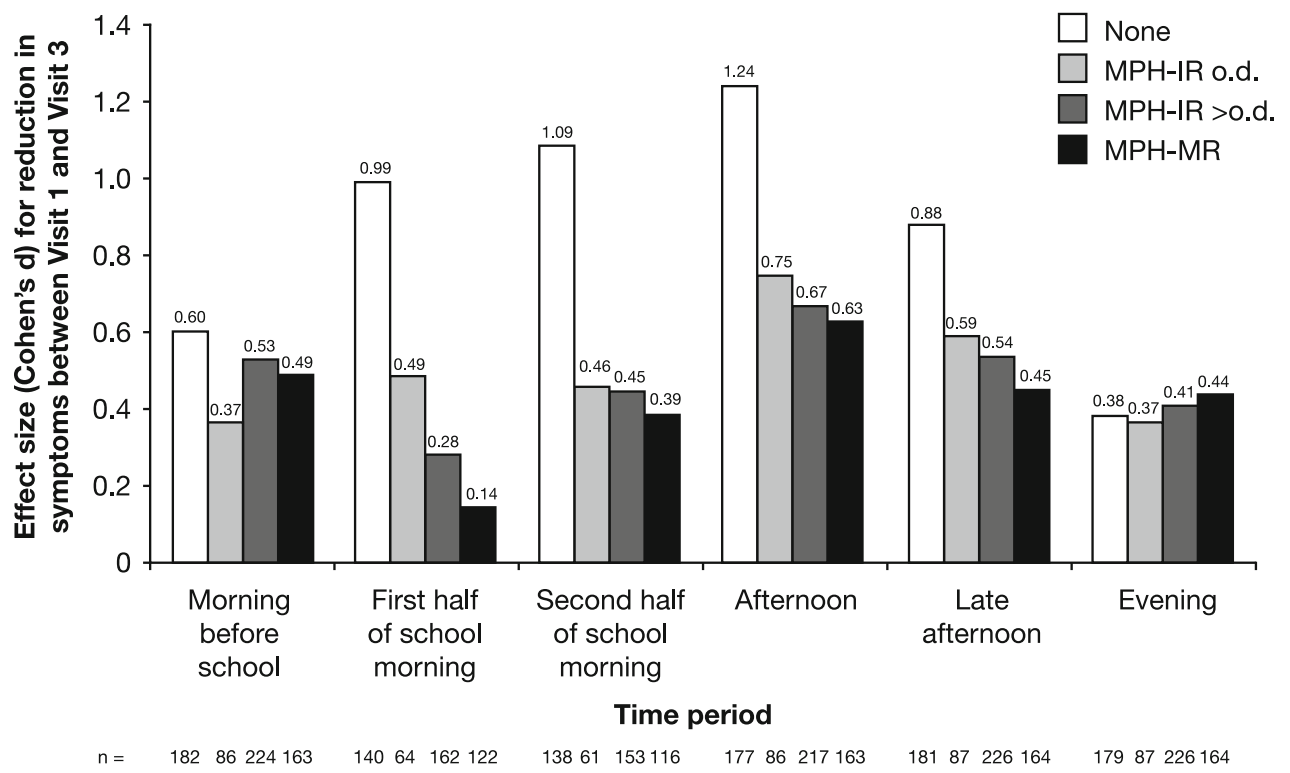

Table 4 Parent (KINDL) and child (KID-KINDL) ratings of QoL stratified by previous medication with main group effect, group-by-time interaction effect (MANOVA) and effect sizes (Cohen's $d$ )

\begin{tabular}{|c|c|c|c|c|c|c|c|c|c|}
\hline \multirow[t]{2}{*}{ Outcome measure } & \multirow[t]{2}{*}{$\begin{array}{l}\text { Previous } \\
\text { medication }\end{array}$} & \multirow[t]{2}{*}{$N$} & \multirow{2}{*}{$\begin{array}{l}\text { Visit } 1 \\
\text { Mean (SD) }\end{array}$} & \multirow{2}{*}{$\begin{array}{l}\text { Visit } 3 \\
\text { Mean (SD) }\end{array}$} & \multicolumn{2}{|c|}{$\begin{array}{l}\text { MANOVA } \\
\text { group }\end{array}$} & \multicolumn{2}{|c|}{$\begin{array}{l}\text { MANOVA group-by-time } \\
\text { interaction }\end{array}$} & \multirow{2}{*}{$\begin{array}{l}\text { Effect size } \\
\text { Cohen's } d \\
\text { (Visit 1-Visit } 3\end{array}$} \\
\hline & & & & & $F$ & $P$ & $F$ & $P$ & \\
\hline \multicolumn{10}{|c|}{ Parent rating of $Q o L(K I N D L)$} \\
\hline \multirow{4}{*}{ Total score } & None & 158 & $61.41(13.82)$ & $72.34(11.25)$ & 2.51 & 0.580 & 5.13 & 0.027 & 0.90 \\
\hline & MPH-IR o.d. & 74 & $60.61(12.92)$ & $70.62(12.53)$ & & & & & 0.74 \\
\hline & MPH-IR >o.d. & 197 & $65.40(13.32)$ & 72.15 (11.39) & & & & & 0.56 \\
\hline & MPH-MR & 136 & $62.90(11.93)$ & $69.24(11.50)$ & & & & & 0.53 \\
\hline \multirow[t]{4}{*}{ Physical well-being } & None & 163 & $72.84(18.54)$ & $78.83(16.62)$ & 0.16 & 0.921 & 0.34 & 0.794 & 0.33 \\
\hline & MPH-IR o.d. & 74 & 71.28 (15.99) & $78.21(18.22)$ & & & & & 0.38 \\
\hline & MPH-IR >o.d. & 201 & $72.08(18.83)$ & $79.48(14.09)$ & & & & & 0.42 \\
\hline & MPH-MR & 137 & $71.03(17.30)$ & $79.09(17.01)$ & & & & & 0.42 \\
\hline \multirow[t]{4}{*}{ Emotional well-being } & None & 163 & $67.73(17.34)$ & $75.61(14.32)$ & 1.05 & 0.371 & 0.85 & 0.467 & 0.46 \\
\hline & MPH-IR o.d. & 74 & $65.03(17.58)$ & $73.73(16.16)$ & & & & & 0.50 \\
\hline & MPH-IR >o.d. & 201 & $69.68(17.48)$ & $75.28(15.50)$ & & & & & 0.31 \\
\hline & MPH-MR & 137 & $67.43(16.72)$ & $74.18(14.48)$ & & & & & 0.45 \\
\hline \multirow[t]{4}{*}{ Self-esteem } & None & 163 & 53.09 (19.59) & $65.50(15.81)$ & 4.00 & 0.008 & 5.39 & 0.001 & 0.66 \\
\hline & MPH-IR o.d. & 74 & $51.41(18.00)$ & $62.33(16.32)$ & & & & & 0.60 \\
\hline & MPH-IR >o.d. & 201 & $58.71(17.64)$ & $65.53(16.31)$ & & & & & 0.39 \\
\hline & MPH-MR & 137 & $54.87(16.63)$ & $59.87(15.39)$ & & & & & 0.29 \\
\hline \multirow[t]{4}{*}{ Family } & None & 163 & $60.20(20.46)$ & $69.93(16.54)$ & 2.43 & 0.065 & 2.15 & 0.930 & 0.56 \\
\hline & MPH-IR o.d. & 74 & $59.68(20.03)$ & $68.22(18.66)$ & & & & & 0.46 \\
\hline & MPH-IR >o.d. & 201 & $65.05(19.14)$ & $71.57(16.62)$ & & & & & 0.37 \\
\hline & MPH SR & 137 & $62.01(17.87)$ & $66.94(16.50)$ & & & & & 0.29 \\
\hline \multirow[t]{4}{*}{ Friends } & None & 163 & $59.83(20.61)$ & 70.64 (16.79) & 0.95 & 0.416 & 3.82 & 0.010 & 0.63 \\
\hline & MPH-IR o.d. & 74 & $57.15(19.48)$ & $69.34(16.62)$ & & & & & 0.57 \\
\hline & MPH-IR >o.d. & 201 & $63.36(20.65)$ & $68.81(18.78)$ & & & & & 0.31 \\
\hline & MPH-MR & 137 & $59.49(21.07)$ & $67.29(17.60)$ & & & & & 0.42 \\
\hline
\end{tabular}


Table 4 continued

\begin{tabular}{|c|c|c|c|c|c|c|c|c|c|}
\hline \multirow[t]{2}{*}{ Outcome measure } & \multirow[t]{2}{*}{$\begin{array}{l}\text { Previous } \\
\text { medication }\end{array}$} & \multirow[t]{2}{*}{$N$} & \multirow{2}{*}{$\begin{array}{l}\text { Visit } 1 \\
\text { Mean (SD) }\end{array}$} & \multirow{2}{*}{$\begin{array}{l}\text { Visit } 3 \\
\text { Mean (SD) }\end{array}$} & \multicolumn{2}{|c|}{$\begin{array}{l}\text { MANOVA } \\
\text { group }\end{array}$} & \multicolumn{2}{|c|}{$\begin{array}{l}\text { MANOVA group-by-time } \\
\text { interaction }\end{array}$} & \multirow{2}{*}{$\begin{array}{l}\text { Effect size } \\
\text { Cohen's } d \\
\text { (Visit 1-Visit 3) }\end{array}$} \\
\hline & & & & & $F$ & $P$ & $F$ & $P$ & \\
\hline \multirow[t]{4}{*}{ School } & None & 158 & $56.34(19.69)$ & $73.62(16.01)$ & 3.19 & 0.023 & 10.95 & 0.000 & 0.87 \\
\hline & MPH-IR o.d. & 74 & $59.12(18.51)$ & $71.90(15.58)$ & & & & & 0.67 \\
\hline & MPH-IR >o.d. & 197 & $64.73(17.38)$ & $73.28(15.57)$ & & & & & 0.49 \\
\hline & MPH-MR & 136 & $61.93(16.42)$ & $68.01(17.05)$ & & & & & 0.36 \\
\hline \multicolumn{10}{|c|}{ Patient rating of QoL (KID-KINDL) } \\
\hline \multirow[t]{4}{*}{ Total score } & None & 120 & $64.00(12.76)$ & $74.56(10.04)$ & 0.49 & 0.690 & 4.87 & 0.002 & 0.91 \\
\hline & MPH-IR o.d. & 60 & $68.37(12.91)$ & $72.97(12.17)$ & & & & & 0.33 \\
\hline & MPH-IR >o.d. & 157 & $67.00(14.13)$ & $73.84(12.30)$ & & & & & 0.48 \\
\hline & MPH-MR & 83 & $67.20(12.25)$ & $71.27(11.87)$ & & & & & 0.31 \\
\hline \multirow[t]{4}{*}{ Physical well-being } & None & 121 & $75.29(18.17)$ & $80.73(15.47)$ & 1.05 & 0.370 & 0.85 & 0.468 & 0.33 \\
\hline & MPH-IR o.d. & 62 & $71.51(14.92)$ & $77.52(15.45)$ & & & & & 0.33 \\
\hline & MPH-IR >o.d. & 158 & $73.60(18.01)$ & $79.51(16.13)$ & & & & & 0.30 \\
\hline & MPH-MR & 85 & $74.39(16.22)$ & $76.59(17.35)$ & & & & & 0.11 \\
\hline \multirow[t]{4}{*}{ Emotional well-being } & None & 121 & $70.14(16.37)$ & $77.01(13.72)$ & 1.07 & 0.362 & 0.85 & 0.470 & 0.41 \\
\hline & MPH-IR o.d. & 62 & $70.60(16.43)$ & $76.41(14.20)$ & & & & & 0.32 \\
\hline & MPH-IR >o.d. & 158 & $73.37(17.32)$ & $78.24(15.08)$ & & & & & 0.27 \\
\hline & MPH-MR & 85 & $71.84(16.47)$ & $74.78(15.92)$ & & & & & 0.16 \\
\hline \multirow[t]{4}{*}{ Self-esteem } & None & 121 & $53.87(20.16)$ & $66.77(17.86)$ & 0.76 & 0.520 & 4.40 & 0.005 & 0.66 \\
\hline & MPH-IR o.d. & 62 & $61.26(18.99)$ & $64.58(21.04)$ & & & & & 0.15 \\
\hline & MPH-IR >o.d. & 158 & $58.95(21.11)$ & $67.29(20.89)$ & & & & & 0.35 \\
\hline & MPH-MR & 85 & $59.63(18.02)$ & $62.94(19.52)$ & & & & & 0.17 \\
\hline \multirow[t]{4}{*}{ Family } & None & 121 & $64.57(19.46)$ & $75.03(15.21)$ & 1.03 & 0.378 & 3.14 & 0.025 & 0.64 \\
\hline & MPH-IR o.d. & 62 & $72.78(18.67)$ & $74.29(17.20)$ & & & & & 0.09 \\
\hline & MPH-IR >o.d. & 158 & $68.95(20.43)$ & 75.59 (16.39) & & & & & 0.33 \\
\hline & MPH-MR & 84 & $66.99(19.76)$ & $74.85(16.12)$ & & & & & 0.37 \\
\hline \multirow[t]{4}{*}{ Friends } & None & 121 & $64.72(20.29)$ & $74.09(17.72)$ & 0.14 & 0.937 & 2.20 & 0.088 & 0.53 \\
\hline & MPH-IR o.d. & 61 & $68.03(20.89)$ & $74.25(21.17)$ & & & & & 0.26 \\
\hline & MPH-IR >o.d. & 158 & $67.38(22.90)$ & $72.46(20.14)$ & & & & & 0.24 \\
\hline & MPH-MR & 85 & $69.12(20.12)$ & $71.32(17.18)$ & & & & & 0.11 \\
\hline \multirow[t]{4}{*}{ School } & None & 120 & $54.27(22.47)$ & $72.41(16.10)$ & 0.46 & 0.711 & 6.46 & 0.000 & 0.82 \\
\hline & MPH-IR o.d. & 61 & $62.77(21.53)$ & $68.95(18.92)$ & & & & & 0.29 \\
\hline & MPH-IR >o.d. & 157 & $60.20(21.73)$ & $70.08(18.53)$ & & & & & 0.43 \\
\hline & MPH-MR & 84 & $62.15(19.37)$ & $68.63(18.70)$ & & & & & 0.30 \\
\hline
\end{tabular}

$I R$ immediate release, KINDL Kinder Lebensqualitätsfragebogen, MANOVA multivariate analysis of variance, $M P H$ methylphenidate, $M R$ modified release, o.d. once daily, $Q o L$ quality of life, $S D$ standard deviation

However, in the present study, slightly lower effects were also found on the DAYAS scale at different periods throughout the day, with the highest effect size (1.24) in the afternoon.

It is interesting to note that on the FBB-ADHD scale, effect sizes in the subgroups with previous medication were smaller in teacher ratings than in parent ratings; this may be due to the fact that in Germany, teachers observed the children only in the morning, when the differences between short- and long-acting medication regimens may be less apparent and, consequently, possibly less perceptible to them than they were to parents. In fact, as shown by its pharmacokinetic profile, Equasym $\mathrm{XL}^{\circledR}$ is characterised by consistent $\mathrm{MPH}$ plasma concentrations and therefore has a consistent effect for over $8 \mathrm{~h}$ after administration [24]; thus, differences relative to short-acting medications would be expected, especially in the afternoon. This is supported by the results obtained on the DAYAS scale, where the strongest symptom reduction compared with previous medication was observed in the afternoon (parent 
Fig. 3 Improvement in QoL from Visit 1 to Visit 3 according to a parent (KINDL) and b patient (KID-KINDL) ratings (subscales with significant group-by-time interactions only) by previous medication subgroup, expressed as effect size (Cohen's $d$ ). KINDL Kinder Lebensqualitätsfragebogen, $I R$ immediate release, $M R$ modified release, $M P H$ methylphenidate, $o . d$. once daily, $Q o L$ quality of life
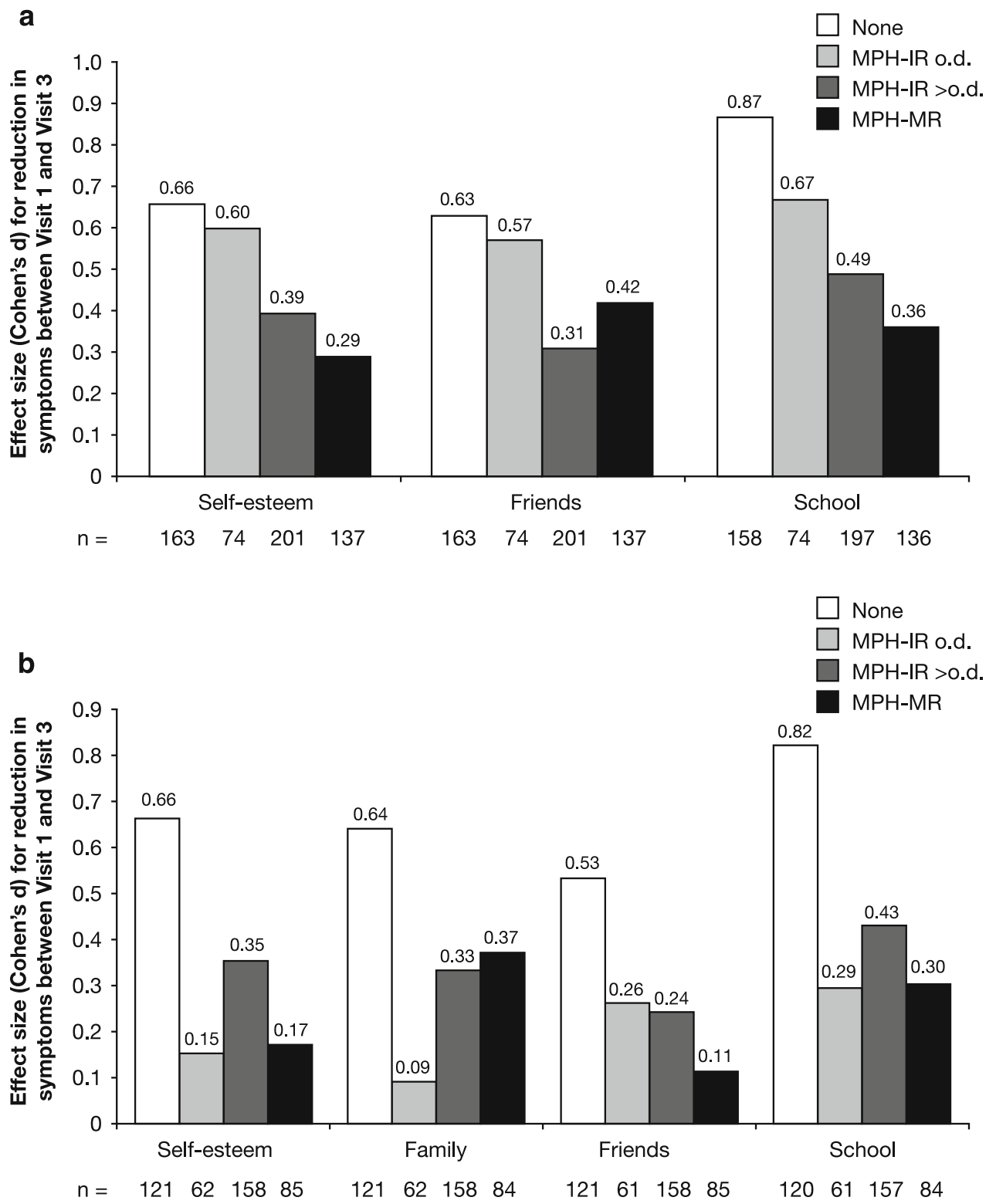

ratings), followed by the morning during school (teacher ratings). The effects in the evening were smaller because the effects of all medications usually diminish and wear off in this part of the day.

To our knowledge, this is the first observational study assessing the differential effects of prior medication status on patient QoL in both parent and patient ratings. The results show differential improvements after switching to Equasym $\mathrm{XL}^{\circledR}$ in several of the QoL domains that are most affected in children with ADHD: self-esteem, friends and school (parent and patient ratings) and family (patient ratings only). The effect sizes for these QoL domains in the treatment-naïve group were about half of those obtained for symptom control (FBB-ADHD); however, they were still in the moderate-to-large range. The effects in the subgroups with previous treatment were smaller but mostly still substantial $(\geq 0.30)$.

The main limitation of this analysis is that, being based on data from an observational study, there was no randomisation, and the subgroups examined were natural groups with different prior treatments. Therefore, it should be taken into account that factors other than previous medication itself may have contributed to the differences observed. Selection bias may also have had an effect on the results of this study, as patients were selected and switched to Equasym $\mathrm{XL}^{\circledR}$ only if the efficacy of the previous medication was insufficient, while children for whom treatment with other MPH formulations was successful were not included. It should be considered, however, that compared with randomised clinical trials, the information 
gained from observational studies reflects real-life situations, and therefore are more directly applicable and extendable to daily clinical practice.

In summary, the effects of Equasym $\mathrm{XL}^{\circledR}$ were greatest for treatment-naïve patients and similar to those found in randomised clinical trials. However, improvements in ADHD symptoms, ODD symptoms and QoL were also observed in subgroups with prior treatment. This suggests that switching to Equasym $\mathrm{XL}^{\circledR}$ may be beneficial even in patients who only achieve suboptimal effects with a different stimulant medication, leading to improved symptom control and QoL, and reduced functional impairment.

Acknowledgments The authors would like to thank Amina Elsner, MD (Shire AG) for constructive review. The OBSEER study was funded by UCB. Additional statistical analyses and the preparation of the manuscript were supported by Shire Development Inc. The authors take full responsibility for the contents of the manuscript but thank Monica Guidi, PhD and Joanna Wright, DPhil (Caudex Medical, Oxford, UK, supported by Shire Development Inc.) for their assistance in preparing the initial draft of the manuscript, including drawing figures and tables, and collating the comments of the authors and other named contributors.

Conflict of interest Manfred Döpfner has received research grants and/or acted as a consultant or on advisory boards for UCB, Lilly, Shire Pharmaceuticals Ltd, Medice and Vifor. Dieter Breuer has been a consultant for Lilly, Shire Pharmaceuticals Ltd, UCB and Medice. Daniel Walter has no conflicts of interest. Aribert Rothenberger has acted as a consultant or on advisory boards and/or as a speaker for Lilly, Shire Pharmaceuticals Ltd, Medice, Novartis and UCB. He has received research support from Shire Pharmaceuticals Ltd, the German Research Society and Schwaabe, and travel and educational grants from Shire Pharmaceuticals Ltd.

This article is part of a supplement sponsored by Shire Development Inc.

Open Access This article is distributed under the terms of the Creative Commons Attribution Noncommercial License which permits any noncommercial use, distribution, and reproduction in any medium, provided the original author(s) and source are credited.

\section{References}

1. American Psychiatric Association (2000) Attention-deficit and disruptive behavior disorders. Attention-deficit/hyperactivity disorder. Diagnostic and statistical manual of mental disorders, 4th edn. American Psychiatric Association, Arlington, pp 85-103

2. Arnold LE, Bozzolo DR, Hodgkins P, McKay M, BeckettThurman L, Greenbaum M, Bukstein O, Patel A (2010) Switching from oral extended-release methylphenidate to the methylphenidate transdermal system: continued attention-deficit/ hyperactivity disorder symptom control and tolerability after abrupt conversion. Curr Med Res Opin 26:129-137

3. Banaschewski T, Coghill D, Santosh P, Zuddas A, Asherson P, Buitelaar J, Danckaerts M, Döpfner M, Faraone SV, Rothenberger A, Sergeant J, Steinhausen HC, Sonuga-Barke EJ, Taylor E (2006) Long-acting medications for the hyperkinetic disorders. A systematic review and European treatment guideline. Eur Child Adolesc Psychiatry 15:476-495
4. Breuer D, Görtz-Dorten A, Rothenberger A, Döpfner M (2011) Assessment of daily profiles of ADHD and ODD symptoms, and symptomatology related to ADHD medication, by parent and teacher ratings. Eur Child Adolesc Psychiatry. doi:10.1007/ s00787-011-0206-0

5. Bruhl B, Döpfner M, Lehmkuhl G (2000) Der Fremdbeurteilungsbogen für hyperkinetische Störungen (FBBHKS)_Prävalenz hyperkinetischer Störrungen im Elternurteil und psychometrische Kriterien. Kindheit Entwicklung 9 S:116-126

6. Bukstein OG, Arnold LE, Landgraf JM, Hodgkins P (2009) Does switching from oral extended-release methylphenidate to the methylphenidate transdermal system affect health-related qualityof-life and medication satisfaction for children with attentiondeficit/hyperactivity disorder? Child Adolesc Psychiatry Ment Health 3:39

7. Cohen J (1988) Statistical power analysis for the behavioural sciences. Lawrence Erlbaum Associates, Hillsdale

8. Döpfner M, Görtz-Dorten A, Breuer D, Rothenberger A (2011) An observational study of once-daily modified-release methylphenidate in ADHD: effectiveness on symptoms and impairment, and safety. Eur Child Adolesc Psychiatry. doi:10.1007/s00787011-0202-4

9. Döpfner M, Breuer D, Ose C, Fischer R (2011) Methylphenidat mit modifizierter Freisetzung in der Routineversorgung-Wirksamkeit und Verträglichkeit eines Methylphenidat-Retard Präparates im klinischen Urteil und im Elternurteil-eine offene multizentrische Studie an Kindern und Jugendlichen mit ADHS. Monatsschrift fur Kinderheilkunde. doi:10.1007/s00112-0112413-7

10. Döpfner M, Gortz-Dorten A, Lehmkuhl G (2008) DiagnostikSystem für psychische Störungen nach ICD-10 und DSM-IV für Kinder- und Jugendliche (DISYPS-II). Huber, Bern

11. Erhart M, Döpfner M, Ravens-Sieberer U (2008) Psychometric properties of two ADHD questionnaires: comparing the Conners' scale and the FBB-HKS in the general population of German children and adolescents - results of the BELLA study. Eur Child Adolesc Psychiatry 17(Suppl 1):106-115

12. Findling RL, Quinn D, Hatch SJ, Cameron SJ, DeCory HH, McDowell M (2006) Comparison of the clinical efficacy of twicedaily Ritalin and once-daily Equasym XL with placebo in children with Attention Deficit/Hyperactivity Disorder. Eur Child Adolesc Psychiatry 15:450-459

13. Horrigan JP, Kohli RR (2002) The impact of dosing frequency on psychostimulant compliance in ADHD. NIMH-42nd annual NCDEU meeting poster 56

14. Morris SB (2008) Estimating effect sizes from pretest-posttestcontrol group designs. Organ Res Methods 11:364-386

15. NIH (2000) National Institutes of Health Consensus Development Conference Statement: diagnosis and treatment of attentiondeficit/hyperactivity disorder (ADHD). J Am Acad Child Adolesc Psychiatry 39:182-193

16. Ravens-Sieberer U, Bullinger M (1998) Assessing health-related quality of life in chronically ill children with the German KINDL: first psychometric and content analytical results. Qual Life Res 7:399-407

17. Remschmidt H, Hoare P, Ettrich C, Rothenberger A, Santosh P, Schmidt M, Spender Q, Tamhne R, Thompson M, Tinline C, Trott GE, Medori R (2005) Symptom control in children and adolescents with attention-deficit/hyperactivity disorder on switching from immediate-release MPH to OROS MPH Results of a 3-week open-label study. Eur Child Adolesc Psychiatry 14:297-304

18. Rosnow RL, Rosenthal R (2009) Effect sizes: why, when and how to use them. J Psychol 217:6-14 
19. Rothenberger A, Becker A, Breuer D, Döpfner M (2011) An observational study of once-daily modified-release methylphenidate in ADHD: quality of life, satisfaction with treatment and adherence. Eur Child Adolesc Psychiatry. doi:10.1007/s00787-011-0203-3

20. Shire. Equasym XL SPC (Europe) 2011

21. Swanson J, Kinsbourne M, Roberts W, Zucker K (1978) Timeresponse analysis of the effect of stimulant medication on the learning ability of children referred for hyperactivity. Pediatrics 61:21-29

22. Swanson JM, Wigal SB, Wigal T, Sonuga-Barke E, Greenhill LL, Biederman J, Kollins S, Nguyen AS, DeCory HH, Hirshe Dirksen SJ, Hatch SJ (2004) A comparison of once-daily extended-release methylphenidate formulations in children with attention-deficit/ hyperactivity disorder in the laboratory school (the Comacs Study). Pediatrics 113:e206-e216

23. Van der Oord S, Prins PJ, Oosterlaan J, Emmelkamp PM (2008) Efficacy of methylphenidate, psychosocial treatments and their combination in school-aged children with ADHD: a meta-analysis. Clin Psychol Rev 28:783-800

24. Wigal SB, Sanchez DY, DeCory HH, D'Imperio JM, Swanson JM (2003) Selection of the optimal dose ratio for a controlleddelivery formulation of methylphenidate. J Appl Res 3:46-63

25. World Health Organization (1992) International classification of diseases (ICD-10), Geneva 